Journal of Agricultural and Environmental Ethics (2006) 19:337-366

DOI 10.1007/s10806-005-5490-6

(C) Springer 2006

BENJAMIN HALE

\title{
THE MORAL CONSIDERABILITY OF INVASIVE TRANSGENIC ANIMALS
}

(Accepted in revised form June 14, 2005)

\begin{abstract}
The term moral considerability refers to the question of whether a being or set of beings is worthy of moral consideration. Moral considerability is most readily afforded to those beings that demonstrate the clearest relationship to rational humans, though many have also argued for and against the moral considerability of species, ecosystems, and "lesser" animals. Among these arguments there are at least two positions: "environmentalist" positions that tend to emphasize the systemic relations between species, and "liberationist" positions that tend to emphasize the attributes or welfare of a particular individual organism. Already, this classic conflict provides for some challenging theoretical clashes between environmentalists and animal liberationists. The question of moral considerability is complicated, however, by recent developments in genetic engineering. Some animals, like pigs and fish, have been genetically modified by humans to grow organs that can then be transplanted into humans. If environmental arguments for the moral consideration of species are correct, then we are released from our obligations to morally consider those animals that we have genetically modified, since they are by their nature always an "invader species." If, instead, the welfare of the animal is of penultimate importance, then there is a case for strengthening the moral considerability of GM animals over "naturally-occurring" animals, since they bear a closer relationship to humans. This would appear to be an intractable problem, a "bad marriage," as Mark Sagoff once proposed. This paper argues that the case of invasive transgenic animals exposes weaknesses in this classic conflict, and particularly, in the framing of this conflict. To remedy this framing problem, this paper argues for a reconceptualization of the term "moral considerability," instead urging a strong distinction between moral considerability, moral relevance, and moral significance.
\end{abstract}

KEY WORDS: considerability, genetic engineering, invader species, moral status, transgenic animals

From this I was aroused, after I know not how long, by a rustling amidst the greenery on the other side of the stream. For a moment I could see nothing but the waving summits of the ferns and reeds. Then suddenly upon the bank of the stream appeared Something - at first I could not distinguish what it was. It bowed its round head to the water, and began to drink. Then I saw it was a man, going on all-fours like a beast. He was clothed in bluish cloth, and was of a copper-coloured hue, with black hair. It seemed that grotesque ugliness was an invariable character of these islanders. I could hear the suck of the water at his lips as he drank.

H.G. Wells, The Island of Dr. Moreau 
Our tradition has so far held that the concept of species should be taken pretty seriously and that the boundaries of a species should be respected. At a popular level, this view is reflected in the symbolism of our myths. Traditional mixed monsters minotaurs, chimeras, lamias, gorgons - stand for a deep and threatening disorder, something not just confusing but dreadful and invasive. Although benign monsters such as Pegasus and archangels are occasionally found, in general the symbolism of mixing species is deeply uncanny and threatening. Even less mixed monsters, such as giants and three-headed dogs, are so framed as to violate the principles of construction that normally make life possible for their species. They too are usually seen as alien and destructive forces.

Mary Midgley, "Biotechnology and Monstrosity"

In the very same year that H. G. Wells published his classic piece The Island of Dr. Moreau, Mahatma Ghandi was coming to terms with the racist practices of the British Empire in South Africa; Marie Curie was discovering the nasty consequences of tinkering with radioactive metals; Henry Ford was emerging from his ramshackle garage to introduce his gasoline-powered motor car, the Quadricycle; and the world was grappling with a spate of wars, from the British conquest of Sudan to the Italian invasion of Abyssinia to uprisings in Crete and Armenia. Also during this period, the debate over Charles Darwin's Origin of Species was raging among educators, philosophers, biologists, theologians, and politicians; Henry Salt was loudly protesting against vivisection; and the social Darwinism of Herbert Spencer was dominating lecture halls. Such developments in the geopolitical landscape, however, could only faintly have hinted at the New World that would follow.

The Island of Dr. Moreau encapsulated the sentiments and fears of the times, drawing on the invasions, the science, the bluster, the threats to religion, and the fear of the unknown that would only grow in intensity as the years progressed through more barbaric wars and more shocking scientific developments. Well's book sketches a scene of gruesome and beastly science-gone-awry, in which the exiled scientist, Dr. Moreau, holed away on a tropical desert island, creates a panoply of cross-stitched humananimal hybrids, sewn together from puzzle-pieces of arms, legs and tails. Through the device of fiction, Wells asks the question that we must now begin to ask ourselves in earnest, because now, Well's nightmare is no longer fiction. Now, in the 21st Century, we have the genetically modified animals of Dr. Moreau's island; now, more urgently, we face the prospect that the inhabitants of Moreau's island could escape their cages, cross the protective ocean, and invade our very landscape. We must ask ourselves, now, What, if any, are our obligations to these creatures? Must we even consider them? 
In ethics, this is sometimes framed as a question about the moral considerability of an entity. The term "moral considerability," therefore, refers to the question of whether a being or set of beings is worthy of moral consideration. Moral considerability is most readily afforded to those beings that demonstrate the clearest relationship to rational humans - like aristocrats, adult men, black slaves, women, and sometimes human fetuses though many have also argued for and against the moral considerability of animals. The discussion of moral considerability has gained particular currency in the area of environmental ethics, and at least two distinct positions have emerged. On one hand, environmentalists tend to focus on the way in which non-human animals figure into the larger environmental landscape, and suggest that non-human animals are morally considerable only insofar as they are component parts of a larger ecosystem. On the other hand, animal liberationists tend to argue that animals are morally considerable because they are living, breathing, and capable of pain, just like we are; because they share salient characteristics with humans. Already, this classic conflict provides for some challenging theoretical clashes between environmentalists and animal ethicists. ${ }^{1}$

The question of moral considerability is complicated, however, by recent human modifications and transformations to the environment and its inhabitants. Some animals, like pigs and fish, have been genetically modified by humans to grow organs that can then be transplanted into humans. On the face of it, one might assume that there is no new ethical question relating to the moral considerability of these animals, since animals are animals, whether genetically modified or not. But upon closer investigation, the issue is much more complex. If environmental arguments for the moral consideration of species are correct, then we are released from our obligations to morally consider those animals that we have genetically modified. In fact, our obligations to GM animals would be

\footnotetext{
${ }^{1}$ One referee has found this comparison objectionable. There are wide variations among environmentalist and liberationist accounts; and in fact many theorists who purport to be environmentalist in their liberationism. Indeed, I take this point seriously. The purpose of the comparison, however, is as much instrumental as it is descriptive. That is, the comparison between the two viewpoints is a simplification based on common assumptions about moral status. This simplification helps to make the point that moral status, when conceived in standard terms, generates contradictions that often cannot be rectified. Rather than engaging specific arguments by specific authors, I am employing a rough simplification of extremely common standpoints. This convention has been employed in the past by such reputable authors as Mark Sagoff, Gary Varner, and J. Baird Callicott. There are other criticisms apropos of authors who attempt to make environmental welfare arguments, though I do not have the space to address these issues in this paper. For more on the conflicts between animal rights and environmental positions, see Callicott (1980), Katz (1983), Sagoff (1984), Norton (1991), Varner (1995), and ultimately, Varner (1998).
} 
non-existent, since they are by their nature always an "invader species." If instead the welfare of the animal is of penultimate importance, then there is a case for strengthening the moral considerability of GM animals over "naturally-occurring" animals, since they bear a closer relationship to humans. This paper asks the question of whether we are released from special obligations to consider the interests of genetically modified animals when they threaten to eradicate the habitat of naturally occurring species. ${ }^{2}$ In doing so, it argues that the complexity of this problem exposes flaws in the framing of the question of moral considerability; and that these flaws in conceptualization lend strength to the ostensibly irreconcilable clash between environmentalists and liberationists. In turn, it urges reconceptualization of the term moral considerability altogether, such that the classic clash between environmentalists and liberationists can be demonstrated to have common roots.

To approach this problem, I first give a background on Genetically Modified, or Transgenic, Organisms, and I introduce the concept of a xenotransplantation-oriented genetically modified animal, or XGMA. I then raise the specific problem of invasive XGMAs, and suggest that this problem introduces inexorable difficulties for standard environmentalist and liberationist moral doctrines. To aid in resolving these problems, I attempt to recast the question of moral considerability as a deontological question as opposed to a metaphysical question - and suggest that the moral status of a being is tied up in the obligation to which we have bound ourselves. Finally, I propose that when we create these animals in our laboratories, we effectively obligate ourselves to be their caregivers, much like we obligate ourselves to be the caregiver of our own offspring, and therefore bear special obligations to these creatures that are not so simply overlooked in the face

\footnotetext{
${ }^{2}$ I am aware of the problem with referring to "native" species as "naturally occurring." Clearly, many species in many parts of the world have interbred and exist as they do because of human intervention; and, as well, there are conceptual problems associated with the use of the term "natural." However, for the purposes of this paper it will not suffice to speak simply of "native" species. Part of the concern with GMOs is that humans have taken the reins from nature and created, intentionally, genetically "artificial" species; not simply that "introduced" species have intermingled with "native" species. Furthermore, almost all discussions of invader species fall subject to the criticism that extracting the human out of nature is a virtual impossibility. However, the conceptual fuzziness of the distinction does not make the distinction pointless for discussions of invader species, and just so should the conceptual fuzziness of the distinction between a "naturally occurring" species, both in genetic origin and in ecosystemic indigenousness, not make the distinction pointless for discussions of GM invader species. Indeed, there are at least strong pragmatic reasons to employ the distinction.
} 
of the vast and potentially disastrous ecosystemic consequences of their release. $^{3}$

The primary purpose of this paper is to investigate the question of whether we are released from special obligations to consider the interests of XGMAs when they threaten to eradicate the habitat of naturally occurring species. Much of the first part of the discussion, therefore, will turn on a clarification of the term "species." A secondary purpose of this paper is to argue that the issue of transgenic animals conflates traditionally rigid conceptual criteria and calls into question, not the criteria, but the nature of the question of moral considerability in the first place.

\section{ORGANISMS, ANIMALS, AND HYBRIDS}

Throughout the environmental and activist literature, there are hot debates regarding the issue of Genetically Modified Organisms, or GMOs. Many of these debates revolve around the potential impacts or consequences of the introduction of GMOs. In recent months, for instance, the European Union has voted to allow the introduction of GM corn, a decision that has emerged from the fog of a tense debate between concerned naturalists and starryeyed futurists.

More perplexing, however, are the issues that relate to Genetically Modified Animals, or GMAs, since animals also present us with the possibility that we must consider them for their own sake. ${ }^{4}$ Animals have feelings and interests in ways that plants do not, and so we must begin now with the hard questions about whether "playing God" on these

\footnotetext{
${ }^{3}$ By "special" obligations I mean nothing more than that the sorts of obligations that we have to XGMAs are peculiar to this class of beings and that they arise out of more-or-less voluntary obligations to which we bind ourselves. Sometimes special obligations are said to emerge from relations between parents and their offspring. The case of XGMAs is considerably more complex, however, since it is not, strictly speaking, a parent-child relation. Instead, it is more generalized: a progenitor-offspring relation, where the progenitors are "we humans" collectively. I argue here that we as a collective, through our direct and indirect actions, have provided the conditions that have made such genetically modified offspring possible; and that hence, we bear responsibilities to the individuals that emerge from our collective actions. Special obligations resulting from parent-child relations are more immediately graspable by virtue of the distinct lineage: parent causes child. In that case, culpability translates into responsibility. Special obligations resulting from progenitor-offspring relations have a similar form - a collective body causes (endorses, allows, encourages) the creation of offspring - but culpability is unattachable to any given participant in the collective. More on the meaning of the collective "we" later.

${ }^{4}$ I am sympathetic with the notion that one must consider plants for their own sake, but for the purposes of this paper, I am depending on the slightly less contentious position that animals must be considered for their own sake.
} 
animals amounts to ethical heresy. In popular culture, the intense ethical debates surrounding the development of GMAs revolve primarily around the use of embryonic stem cells, around the morality of tampering with the divine order of things, around the prospect of cataclysmic interruptions in the ecosystemic fabric, and so on (Rollin, 1995). But these are clearly not the only, nor perhaps even the most, important issues. To understand the multidimensional problem appropriately, one must make scientifically informed and conceptually critical distinctions between the types of GMAs.

To this end, there are at least two relevant categories of GMAs: the first category treats animals as though they are crops, like lettuce or carrots, and so modifies the animal to produce more of its product. Cows are treated genetically to produce more meat, tender flesh, more milk; pigs are treated genetically to develop lower fat and lower cholesterol meats; fish are treated genetically so that they glow underwater, and so on. ${ }^{5}$ These I will refer to as simple GMAs. In a way, the genetic modification done on these animals is not altogether different than the selective breeding modifications that have been done for centuries to produce numerous domesticated animals. I will, therefore, not address the ethical implications of their production in this paper. ${ }^{6}$ But the second category of GMAs treats animals as though they are organ production laboratories. These transgenic animals are used to grow human organs - skin, blood, livers, and so on - for transplantation into humans. In this case, the end-goal is xenotransplantation, cross-species transplantation, and we seek not a product, but a replacement part. These xenotransplantation-oriented GMAs present slightly different problems for us, because the technology is very new, and the end-result, well, comes right off the pages of science fiction. I will

\footnotetext{
${ }^{5}$ See, for instance: Conner, Steve, "Scientists Could Make GM Beef with Healthy Fish Oils," The Independent, February 5, 2004; Highfield, Roger, "How I chopped the fat from bacon... Wilbur the $300 \mathrm{~kg}$ boar will help farmers to breed leaner, tastier, more profitable animals," The Daily Telegraph, London, Nov 26, 2003, pp. 20; Pollack, Andrew, "So the Fish Glow, but Will They Sell?" New York Times, Jan 25, 2004 pBU5 Col. 01.

${ }^{6}$ Note that there is perhaps a subcategory of GMAs. That is, some animals are transgenic by means of splicing organisms of differing taxonomic kingdoms together (as opposed to animals that are crossed with other members of the animal kingdom), such as the famous FlavrSavr $^{\mathrm{TM}}$ tomatoes that have been spliced with the fish gene, mice that have been crossed with the malaria virus to produce a vaccine in their milk, and goats that have been crossed with spider genes to produce fantastically strong spider webs. See, for instance: (Stowers et al., 2001).
} 
abbreviate these sorts of GMAs with XGMA. These are the sorts of animals about which I am the most concerned in this paper. ${ }^{7}$

If there is one outstanding characteristic of XGMAs, it is that they are hybrid creatures: part animal, part human. In some circles, the resultant organisms are considered to be "chimeras" - mystical creatures plucked from the pages of ancient mythology - though the term "chimera" does not clearly distinguish between simple GMAs and XGMAs. By their very composition, XGMAs blur the already blurry boundary between human and non-human animals, and further, call into question the moral significance of the XGMA itself, since its function as an organ production laboratory is more akin to a holding tank or a coat rack than a living, breathing animal. Why do they blur this boundary? Because with transgenic xenotransplantation there are two moments of crossover. In the first set of transmogrifications, human genes are transferred to the healthy chromosomes of a related mammal. In the second set of transmogrifications, the organs that are grown through the host mammal are removed, the host mammal is either killed or severely debilitated, and the organs are reinstalled in the donor. The XGMAs act as mere vehicles or potting soil for the appropriate organs.

In a recent article on transgenic animals in the American Journal of Bioethics, Jason Scott Robert and François Baylis mention four main instances of XGMA uses:

\footnotetext{
${ }^{7}$ One might wonder why I would be concerned specifically with XGMAs and not with GMAs in general. The reason for this is primarily pragmatic, as many of these arguments might also apply to any GMO. However, there are some salient distinctions that bear discussion. First, there is a qualitative difference between an animal that has been brought about through "natural" means and an animal that has been brought about through "artificial" or "intentional" means. The debate about the meaning of "natural" (whether metaphysical, real, or lay) notwithstanding, there are good reasons to bear this in mind when making a decision about what to do with the natural world. Namely, we (individually and collectively) are presumably culpable for intentional actions in ways that we are not culpable for accidental actions. Second, it is a common error of philosophers and activists, I think, to be too general about entities under consideration and not to focus on particulars. For instance, animal liberationists who argue for the full rights of all laboratory animals regardless of the use to which the animal is being put, I would say, are both undermining the strength of their argument - is there really no morally relevant difference between a rabbit that is experimented upon in a cancer study and a rabbit that is experimented upon in a cosmetics study? - and undermining the degree to which their claims will have practical force - that there is a difference leaves the door open for opponents of animal welfare to argue, on grounds that since some cancer experiments appear justified (or at least more justifiable than non-medical experiments), then all animal experiments are justified. That said, I am, of course, still making a generalization by arguing that there is a distinction between those animals that we (humans) create intentionally and with our own genes and those animals that we create intentionally and with the genes of other animals. Indeed, the generalization could be parsed more finely, but the intent of my distinction, it will become apparent, is to try to imagine a situation in which the XGMAs are, in the important respects, like our offspring. What are these important respects? Primarily, that they are both (a) intentionally created by us and (b) genetically related to us.
} 
Snyder and colleagues at Harvard have transplanted human neural stem cells into the forebrain of a developing bonnet monkey in order to assess stem cell function in development (Ourednik et al., 2001); human embryonic stem cells have been inserted into young chick embryos by Benvenisty and colleagues at the Hebrew University of Jerusalem (Goldstein et al., 2002); and most recently it has been reported that human genetic material has been transferred into rabbit eggs by Sheng (Dennis, 2002), while Weissman and colleagues at Stanford University and StemCells, Inc., have created a mouse with a significant proportion of human stem cells in its brain (Krieger, 2002).

Already since the printing of the above article, there have been many more developments worth noting. Recently, for instance, scientists and doctors at Massachusetts General Hospital in Cambridge have been able to successfully transplant pig-grown GM kidneys into baboons. ${ }^{8}$ In a recent Mother Jones article, Mark Dowie tells the tale of Dr. Stewart Newman, a modern day Dr. Moreau, who applied in 1998 for a patent on a humananimal Chimera (Dowie, 2004).

To be fair, many of the first generation of XGMAs have been used not for the purposes of developing organs for transplantation into humans, but rather to create more accurate testing templates for human study. XGM Mice, for instance, have been studied at NIH to determine the carcinogenicity of certain toxins to humans (Tennant et al., 1999). Indeed, at present, the experimental benefits are perhaps more hopeful than the somewhat futuristic claims of eventual organ development. (This issue has been taken up productively by Bernard Rollin (1995), who, citing the practical inevitability of the use of human-animal medical templates, thinks that the only ethically acceptable compromise in these cases is to generate XGMAs that have the epidemiologically relevant characteristics of humans, but that have been "decerebratized" and anaesthetized to feel no pain and to have no subjective experiences whatsoever.)

For all of the promise of such research - which is more or less evident to those who can imagine the uses to which such nascent technologies can be put - there is also a somewhat instinctive revulsion. This has been dubbed the "Yuck" Factor by Mary Midgley (2000), who thinks that we ought to listen more attentively to ourselves when we feel these yuck-inclined misgivings. Indeed, this Yuck factor is played up in popular culture, to such a degree that it is often difficult to determine what, exactly, the real ethical issues are. From a pragmatic standpoint, it may make good sense for us to listen to our intuitions. However, there are far more axiomatic and principled objections to XGMA technology than pat rejection of it. One might argue, as I do below, that one reason to attend to XGMAs is that they are our non-accidental creations and that they share important relational similarities with our offspring.

\footnotetext{
8 "Breakthrough in GM Organ Transplant," The Guardian, Dec 11, 2003, pp. 7.
} 
Robert and Baylis's article (2003) laments that the introduction of transgenic species will "introduce inexorable moral confusion in our existing relationships with nonhuman animals and in our future relationships with part-human hybrids and chimeras." Their article has resulted in a flood of commentary from thinkers throughout the bioethical establishment. Hilary Bok, for instance, rejects Robert's and Baylis's worry about the confusion of the meaning of the term "species" by appealing to our intuitions about human beings (Bok, 2003). We simply know a human when we see one, she thinks, and unless there are exceptionally significant genetic similarities between XGMAs and humans, then we will have no reason to be confused at all. Jill Didur (2003) points out that critical posthumanists like Donna Haraway question "the view that there was ever an originary divide between these things in the first place." Still others claim, as Andrew Siegel (2003) does, that XGMAs do not actually call into question much at all, since the assumption that humanness is necessary for personhood was already called into question long ago. But Siegel, at least, does so with the understanding that being a human - that is, having "one hundred percent" human genetic material - is not sufficient to be considered a person. He thinks that it is far more common to encounter the position that advanced cognitive capacities, not biological humanness, are sufficient for personhood. The real test, he thinks, will be if they can think.

Indeed, many have already persuasively objected to biological humanness as a baseline criterion for personhood (Siegel, 2003). While I can certainly agree with Siegel's criticism of Robert and Baylis, I do not agree that the attribute of having advanced cognitive capacities has so clearly been established as the grounding criterion for determination of moral status. Such a point has been argued repeatedly by authors ranging form Peter Singer to Bernard Rollin to Aldo Leopold, and there is little reason to adopt the rational-anthropocentric line of argument to defend the claim that these creatures pose no new ethical problems for us.

Further, such developments call into question the hard-and-fast categories of evolutionary biology. While the category of "humanness" might once have been thought an immutable and static given, in the face of human-nonhuman transgenic modification, it is subject to question in much the same way that the category of "race," in the face of miscegenation, has been called into question. ${ }^{9}$ Where it was once thought that race was an immutable and essential category - indeed, the term "race" was used interchangeably with the term "species" in many early biological texts such essentialist, "one drop" theories have been shown to be fallacious

\footnotetext{
${ }^{9}$ Daniel Dennett explains that one of Darwin's first, and arguably most important, contributions to biology was to challenge the idea that "species" was an immutable, timeless given. See: (Dennett, 1995, 35-39).
} 
prejudices on the part of adherents (Gould, 1981). Nobody really considers races to be hard metaphysical categories anymore. At best, they are demographic and epidemiological tools, conceptual devices that help us make sense of general tendencies within genetically similar cohorts of humans.

\section{THE PROBLEM OF INVASIVE XGMAS}

The question of invasive genetically altered species has so far been raised only in relation to simple GMOs, and only loosely in reference to simple GMAs. This is probably due to the nature of the technology. Until recently, very few GMOs and GMAs posed any real risk to naturally occurring ecosystems. ${ }^{10}$ Alarm spread in 2001, however, when the Bostonbased company Aquagenics proposed to begin farming transgenic AuqAdvantage $^{\mathrm{TM}}$ Atlantic salmon in coastal waters. The Union of Concerned Scientists immediately beseeched the US Government to take a harder look at the environmental impacts of the salmon before approving their edibility. ${ }^{11}$

Such alarm is well-founded. The National Research Council of the National Academy of Sciences released a report in early 2004 that found that "while there are many techniques being developed to prevent genetically engineered organisms or their genes from escaping into the wild, most techniques are still in early development and none appear to be completely effective" (Pollack, 2004b). Gregory Jaffe of the Center for Science in the Public Interest said the report's conclusion that there is no foolproof bioconfinement method suggests that "there is a need to have a better regulatory system that assesses whether there are any risks to begin with" (Pollack, 2004b).

The possibility of GMAs and GMOs escaping into the environment threatens serious consequences that most farmers and developers of genetically modified technologies would like to prevent. Raymond Carruthers, the head of one of the largest USDA biological control facilities, has recently characterized invasive species as a "horrific and increasing problem" (Carruthers, 2004). David Lodge and Kristin Shrader-Frechette have argued that there is little disagreement about the problems with non-indigenous species, but that the main ethical and policy issue lies in the sorts of risk assessment protocols that could be acceptable to a large constituency

\footnotetext{
${ }^{10}$ For reference, see: "Purdue Scientists: Genetically Modified Fish Could Damage Ecology," AScribe Newswire, February 23, 2004 Monday.

${ }^{11}$ Union of Concerned Scientists, "Genetically Engineered Salmon," February 1, 2001, http://www.ucsusa.org/food_and_environment/biotechnology/page.cfm?pageID = 327 .
} 
(Lodge and Shrader-Frechette, 2003). In fact, it is important to recognize that most objections to any sort of invader species are consequentially based.

The case of invasive XGMAs presents an especially complex problem, however, because we philosophers have historically placed asymmetrically heavy emphasis on the moral priority of humans, and on the natural, untamperedness of nature. Almost instinctively, one is inclined to revert to the Yuck objections that Midgely discusses, since the image evokes fears of alien, half-human monsters roaming the once-pristine landscape. Indeed, the outlandish and unnatural oddity of the invader GMAs is an incredibly appropriate objection to the development of GMAs and their invasion of the landscape.

At a certain level, invader species have always been considered "unnatural." The US Federal Government defines an invader species as "a species that is (1) non-native (or alien) to the ecosystem under consideration and (2) whose introduction causes or is likely to cause economic or environmental harm or harm to human health." 12 If GM corn infiltrates a crop of maize, for instance, farmers can then argue that the natural corn has been tainted. What constitutes the "natural" or "baseline" state of the ecosystem is left up to experts and specialists, and is certainly open for dispute. Farmers take steps to eradicate this invader species in order to preserve the organic purity of the natural crop. Invasive species on these grounds can only be thought to be invasive if the plants or animals produce reproductive offspring (Richardson et al., 2000). (It is a pleasant irony that corn itself has never been natural, but is a hybridized grain.) They must, in other words, colonize, or attempt to colonize, a given ecosystem. As they do this, of course, they gradually become naturalized themselves, and the landscape of the given ecosystem shifts, calling into question the very idea of what is a natural feature of the ecosystem.

It is also true, however, that GMOs are considered to be "unnatural" by their very development. What is natural on this basis is considered to be anything that has evolved or emerged without the intervention of genetic manipulation. One might say that Invasive GMOs are therefore twice unnatural, because they are both unwelcome in their particular ecosystem and unnatural in the sense that they have been modified by humans.

The question of what is and what is not "natural" has been addressed by numerous authors in the past. I do not intend to invoke this discussion here. It is too complex and it depends on a certain teleological view

\footnotetext{
${ }^{12}$ Executive Order 13112. For an incredibly comprehensive website related to US Government policy on the matter of invasive species, visit: http://www.invasivespecies.gov
} 
of the world that has generated a minor continent of literature. Plus, the mere existence of these creatures in laboratories and factories might already be seen as a kind of unnatural invasion of the environment. Indeed, XGMAs are here, in our presence, and they are real enough that we must attend to the sundry ethical concerns that surround them. But this too is not at issue. Rather, I am considering the case in which beings that have been created by us, beings that might be considered our own very offspring, escape into the ecosystem, like so many seeds of GMO plants, and begin to utilize the resources of the rest of the ecosystem and community. These animals could inflict untold damage to our present ecosystems, and those who would want to protect the environment seem ill-equipped to do so.

\section{THE META-ETHICAL CONFLICT: ENVIRONMENTALISTS VS. ANIMAL LIBERATIONISTS}

There are at least two ethical debates that are relevant to this issue. The first debate might be characterized as the classic debate between animal liberationists and environmentalists, where the second debate revolves around the criterion that one might use to establish which beings are morally worthy. We shall discuss the first debate in this section.

Where many animal liberationists argue that each individual animal is worthy of moral consideration in its own right, many environmentalists argue that no single individual within the system is what matters, but rather that it is the ecosystem or the species as a whole that matters. ${ }^{13} \mathrm{We}$ might characterize this as the classic "individual/system debate." This debate gains great importance when covering the topic of invader species, which, according to the liberationist way of thinking, ought to be treated as just a grouping of independently valuable individuals. According to the environmentalist way of thinking, however, invaders to any given ecosystem ought always to be treated as intruders.

The logic of moral considerability according to this debate works like this: An environmentalist might argue that the reason that we must consider Being $X$ is because that being is a member of a particular Species $\alpha$, which is a group that deserves moral consideration. She might give any number of reasons why that being deserves moral consideration, ranging from

\footnotetext{
${ }^{13}$ It is perhaps unfair to characterize all environmentalists as subscribing to this position. I have in mind here some of the more ecosystem-oriented environmentalists, like the deep ecologists and the wilderness theorists, though such theorists often also profess a biocentric egalitarianism in which all animals are considered equal. For an intelligent and brief discussion of the history of this debate, see Varner (1995).
} 
sentience to consciousness to rationality to endangeredness, but she could conclude from her argument that Being $\mathrm{X}$, as a member of the Species $\alpha$, also deserves moral consideration. This is a very common way of arguing that some particular group of entities deserves some moral status, and in fact the way that most Kantians and Utilitarians might argue the point even outside of environmental concerns. ${ }^{14}$ On the other hand, however, an animal liberationist might argue that the reason that we must consider Being $\mathrm{X}$ is not because that being is a member of Species $\alpha$, but instead because that being has characteristics or attributes that make it morally considerable in its own right. ${ }^{15}$ Sometimes, curiously, these characteristics or attributes are exactly the same attributes that the environmentalist will cite.

For instance, the sus scrofa, the wild boar, is not indigenous to the island of Hawaii, an ecosystem rich with evolutionarily unique species. Local environmentalists argue vehemently about the scourge of the feral boars and suggest that the pugnacious porcines are occupying habitat that is critical to the survival of endangered or native species. ${ }^{16}$ They then suggest numerous solutions, some of which are rather nasty and aggressive, to eradicate boars from these habitats. Animal liberationists, on the other hand, reason that we have obligations to protect each individual being, and so therefore ought not to take steps that call for the eradication of the invader species, no matter how much of a threat they pose to the ecosystem.

On the face of it, these two positions seem irreconcilable. Mark Sagoff and J. Baird Callicott, environmental ethicists of differing backgrounds and ecological dispositions, argue in two important essays that environmentalists and animal liberationists share incompatible positions, and that the liberationist position can never be fruitful for an environmental ethic (Callicott, 1980; Sagoff, 1984). Bryan Norton (1991, p. 222), an environmentalist of a more pragmatic stripe, has devoted much of his writing to seeking common ground among environmentalists, but also thinks that little can be done to reconcile these two positions.

\footnotetext{
14 The United States Endangered Species Act, it can be argued, is based upon just such reasoning: that the endangeredness or threatenedness of a given species, and not any particular instance or attribute of that species, is enough to warrant the granting of status to that species. The position is taken up by theorists who typically identify themselves as environmental "holists," meaning that they attribute value to the individual by virtue of the individual's relation to the greater ecosystem or whole. Aldo Leopold, J. Baird Callicott, and Arne Naess are sometimes clustered in the environmental holist camp.

15 Peter Singer and Tom Regan are the clearest and best known representatives of this position, though many other biocentric individualists have also taken up this stance.

16 "Feral Pigs Wrecking Tantalus Ecology," Honolulu Star-Bulletin, March 25, 2002.
} 
Looking a little closer, however, we can see a kind of two-sidedness to the theories of environmentalists. On one hand, they emphasize the system over the individual; but on the other hand, they recognize kinship among members of a family or tribe. ${ }^{17}$ On one hand, they will argue for the preservation of wilderness; but on the other hand they will argue for the preservation of species (just think of the importance of the "species" concept to the Endangered Species Act). The same appears to be true of the animal liberationists. On one hand, they emphasize the interests of the individual over the system; but on the other hand, they too recognize kinship among members of a family, tribe or species, and recognize that sometimes the interests of the general group outweigh the interests of any individual within that group. ${ }^{18}$ Minimally, there are generally accepted limits on the degree to which the needs of the ecosystem or the individual can impinge on the lives of rational human persons. Only the most extreme environmentalists will argue that rational human persons, for instance, must be treated as just another feature of the landscape. ${ }^{19}$ Only the most extreme animal liberationists will argue that, given the choice of whether to provide medical care for a rational human person or a dog, that there is no patently obvious solution. Both, it appears, maintain a sort of stewardship model of obligation, in which the rational and ethical actor - the human agent, in this case - must steward the interests of beings that cannot otherwise express their interests.

So, return to the example of the sus scrofa in Hawaii. Some local environmentalists argue that the unique Hawaiian ecosystem ought to be of primary importance when determining what to do about the invasion.

\footnotetext{
${ }^{17}$ Callicott has perhaps taken this claim the furthest (1988: 186-214). He seeks to explain why we can maintain a strong environmental ethic but also hold strong obligations to members of our family. Drawing from Aldo Leopold, Charles Darwin, and David Hume, Callicott attempts to show how our moral sensibilities can inform our obligations to entities in spheres of decreasing relation to us. As entities get further from our evolutionary and personal core, Callicott claims, our obligations to them diminish, but never fade into nothingness. Says Callicott: "Family obligations in general come before nationalistic duties and humanitarian obligations in general come before environmental duties" (1988: 208). The hypothesis that I am presenting here will accommodate the varying degrees of moral strength that is attractive about Callicott's metaphor, but it does not rely on evolutionary biology or Humean sentiments for its normative force.

${ }^{18}$ This is not true for everyone, of course. I am speaking in broad strokes to carve out a space for the position that I am advancing. To address the nuances of each position would take pages.

${ }^{19}$ Edward Abbey is reputed to have advocated suicide over environmental destruction, though I cannot find a direct citation for this.
} 
They reason that feral pigs should be culled in order to preserve the ecosystem. In their haste, some even reason that the pigs should be trapped, hunted, and shot. ${ }^{20}$ When they reason this, they do so to the exclusion of the interests and welfare of individual pigs. Proponents of this position might justify their stance by reasoning that "Pigs are just pigs," that pigs have no moral standing whatsoever; or that the concerns of the environment absolutely overshadow the standing of the pigs. But their use of the term "just" betrays their disingenuousness. Even the staunchest environmentalist, when pressed, I would think, would have difficulty saying that the wild sus scrofa are "just pigs," since this implies, in part, that pigs have no standing whatsoever. On this reasoning, being "just a pig" is equivalent with being "just a can of paint," which is certainly not true. Pigs differ significantly from cans of paint, and they differ in ways that should resonate with some of the principles of the environmentalist. Similarly, liberationists who think that the sus scrofa have rights over and above the rights of the unique Hawaiian ecosystem, might reason that the environment is "just a backdrop, a background." If they do this, they rely on equivalently disingenuous employment of the use of the imperial "just." The environment is more than "just a backdrop," since it is not, in fact, a backdrop. Sus scrofa could not survive on movie sound stages. The native Hawaiian ecosystem differs significantly from a backdrop, and it differs in ways that should resonate with some of the principles of the liberationist. But conceiving of moral status as an on/off proposition - either one has it, or one does not have it - enables both stances to get away with disregarding the concerns of the other.

Alone, neither of these two positions will be sufficient for the condemnation or acceptance of the dilemma of invader XGMAs, since XGMAs embody many of the concerns of both positions. If we look instead to the necessary presuppositions of the two positions, however - which is a general belief that one must take responsibility for one's actions - then I think we can find a middle ground. If there is one principle that is predominant in environmentalist thinking it is that we are responsible for our actions, and that, if we create a mess, we should do what we can to clean it up. This is also true of much liberationist thinking: that we must take responsibility for our actions and not harm any particular individual, if we can help it. This

\footnotetext{
${ }^{20}$ Reginald Barrett, of the Department of Environmental Science, Policy and Management at the University of California at Berkeley, and Grant Birmingham, of the US Department of Agriculture, explain the best method for killing feral pigs: "A well-placed shot to the head from a large-caliber rifle will kill the hog instantly without greatly alarming other hogs in the trap. Shoot the largest hog first, if possible." (Barrett and Birmingham, 1994)
} 
suggests an emphasis on responsibility for one's actions, a sort of deontological intuition that underlies all of the talk about individuals and species and habitat. Both of the two positions, I believe, implicitly depend upon the supposition, though they do not explicitly state it, that we must take responsibility for our actions to other beings. The liberationist model proposes that all animals are equal, and denies, at least in theory, that we should have special obligations to our own offspring. The environmentalist model proposes that all members of an ecosystem are only as valuable as the ecosystem in which they are located, such that we should not interfere with the biotic community. Both, however, insist that we must take responsibility for our actions by taking factors outside of our immediate interests into moral consideration.

\section{MORAL CONSIDERABILITY, MORAL RELEVANCE, AND MORAL SIGNIFICANCE}

The second debate, and the debate that falls on the heels of the above observation, revolves around the criterion of moral status for genetically modified organisms. There are three positions that one might take on this issue. The first position relates to the organism as it is in itself. One might be inclined to suggest that, ceteris paribus, ${ }^{21} \mathrm{GM}$ organisms differ in no significant regard from other naturally occurring organisms. A ficus is a ficus, whether it grows in the forest or is grown in a lab. Criteria for consideration of individuals of these species should be no different than criteria for any other species. The second position suggests that GM organisms differ insofar as they are unnatural and artificial. In this case, the artificiality of the organism suggests that it might be less considerable, or not considerable at all, because it has been created by humans to serve a purpose, in much the same way that tools and instruments are created by humans to serve a purpose. Finally, the third position suggests that GM organisms differ from natural organisms insofar as they are the offspring of humans, and therefore, like children, that they deserve greater moral consideration. In what follows, I will be arguing for the perspective of the third position, on

\footnotetext{
${ }^{21}$ Why ceteris paribus? Because the criteria for moral considerability are manifold, and many of them do not apply when comparing apples to apples. Some, for instance, argue that only those beings that have rationality ought to be considered morally. In the case of GMOs, neither of the two organisms could be said to have rationality, and so therefore would fall under this first cluster of positions.
} 
grounds that our ratification and endorsement of their existence obligates us to consider their interests. ${ }^{22}$

Over the years, theorists have devised innumerable criteria that specify what is so special about humans. Julian Savulescu (2003) lists some of the many criteria that have been used to establish the moral status of humans over and above non-human animals. Some of these include

1. capacity to reason

2. capacity to act from normative reasons, including moral reasons

3. capacity to act autonomously

4. capacity to engage in complex social relationships

5. capacity to display empathy and sympathy

6. capacity to have faith (believe in a god)

The list is hardly comprehensive, but it does point to some of the creative ways in which humans have sought to distinguish themselves from other living organisms. One of the implications of assuming attributes such as these as qualifying attributes is that those beings that do not exhibit the attribute can be forgotten about. So, examine how this works. If we say that the capacity to reason is the qualifying attribute for establishing moral status, then we can forget asking ourselves any questions about beings that cannot reason. If we say that having a welfare is the qualifying attribute, then we can forget having interests. If we say that having interests is the qualifying attribute, then we can forget having ecosystemic dependent relations. Yet if we expand it further, if we say that having ecosystemic dependent relations is a qualifying attribute, then we can either forget all entities that exist in isolation or we will have to give special dispensation to those attributes that might seem more important to some creatures than ecosystemic dependent relations, like capacity to reason, for instance. Otherwise, we will be forced to the incredibly radical conclusions of some deep ecologists who, ostensibly, propose that the life of any single human is worth only as much as the existence of any single rock. We will be forced to concur with the most extreme interpretations of wilderness theorists like

\footnotetext{
${ }^{22}$ By "our" here I mean "we human creators of XGMAs." My use of the term is collective, much like, in a discussion of nuclear power, if I were to refer to "our" ratification and endorsement of nuclear energy. I would mean by this "we human creators of nuclear power," and in meaning this, I would mean that we members of the human collective have an obligation because of actions that other members of our collective have undertaken. One might object, however, that the sorts of obligations that we have to our own offspring are precisely not collective obligations. I have obligations to my child mostly because I myself have taken steps to bring that child into the world. As I mention earlier, however, there is a fine but important distinction between culpability and responsibility, and in this case, it seems to me entirely reasonable to suggest that sometimes we bear obligations to entities that any one of us individually and single-handedly have not taken steps to bring into the world.
} 
Aldo Leopold, J. Baird Callicott, and William Cronon who propose that "a thing is right when it tends to preserve the integrity, stability, and beauty of the biotic community" (Leopold, 1966; Cronon, 1996; Callicott, 1998).

Observing the problematic assertions of previous attempts to isolate the true question of moral considerability, Mary Ann Warren has endorsed a "multi-criterial" approach to moral status in her superb and influential book Moral Status (Warren, 1997). Her approach, unfortunately, forces her into the awkward position of positing different levels of status, suggesting that some entities have partial moral status while others have full moral status or no moral status. The clear problem with the way in which the debate is now framed is that it forces us into a position in which we must run through the various definitions of and attributes intrinsic to humanness in order to clearly establish the moral specialness of a given entity. Robert and Baylis (2003) express concern about the blurring of these classic distinctions in their controversial article. They may be right to be concerned about the definition of species, but it is hardly a convincing argument that we ought not to engage in the development of XGMAs simply because we won't know what to do with them once we realize that our precious categories are challenged.

What all of these preceding complications point to, in my mind, is not a need to refurbish our account of what is required to be a human, and consequently, what is required to qualify for personhood, but rather a need to dramatically rethink the question of moral considerability altogether. That is to say, historically, the question of moral considerability has been thought to be just another way to ask the question of moral status. What matters morally, or what should be morally considered, on this view, has been understood as a question about which set of criteria is the appropriate set of criteria to distinguish one group from another. But I think the question of moral considerability must be rethought entirely.

I have argued in other places that moral considerability is better understood as a question that rational agents ask themselves about their obligations to others. ${ }^{23}$ This issue is illustrated well by the conflict that emerges between the liberationist and the environmentalist positions in light of invasive XGMAs. If we conceive of moral considerability not as a question about the rights or the welfare of the animal, but rather as a question about how one should go about considering the entities in question, then we can avoid some of the apparent conflicts between the two views.

Think of it this way. When asking questions of moral status, we can ask ourselves three questions:

\footnotetext{
${ }^{23}$ For the most elaborate and respectively concise discussion of this view, see my doctoral dissertation, The Roots of Moral Considerability (2004).
} 
1. What or which entities must we consider, and why must we consider them?

2. If we must consider them, then what must we consider about them?

3. How much must we consider them or, differently put, how much weight must we give to these considerations?

The first question relates to the question of moral consideration: what or which entities must we consider, and why must we consider them? The following two questions relate to the question of moral relevance and moral significance, respectively. The question of moral status as traditionally conceived attempts to answer all three questions at once, telling us which entities we must consider by virtue of which attributes and according to the degrees to which those attributes are relevant. ${ }^{24}$

For instance, one might argue that we must take animals like dogs into moral consideration. When one says this, he is answering the first question. It could be the case, in other words, that animals would have interests, like other humans might have interests, but we simply need not be concerned about those interests to determine whether the animal is morally considerable. My tendency is think that we must consider all entities that make up our environment, including abstract entities like species and mountains, and I argue for this elsewhere. "Must I consider dogs morally? Yes?" Well, we can move on to the next question. This answers the question of moral consideration.

One might then specify that we must be concerned for their welfare, for their feelings, for their concerns, however we might define or understand these, but not their training in linear algebra, since the mathematics education of dogs seems altogether ridiculous. When one suggests this, one is answering the second question, about moral relevance. In this case, the claim relates to certain aspects or features of the existence of the entities that are relevant to the consideration of them. There are a number of ways in which this question can be answered, but we'll leave the answer to this question up to the cognitive scientists and phenomenologists.

\footnotetext{
${ }^{24}$ One referee is concerned that we cannot know how to answer this question "without paying any attention to the characteristics of those who are potential objects of our obligation." This is a common concern expressed by those who continue to view moral consideration as synonymous with moral status. However, it is the purpose of this distinction to argue that moral considerability need not be affixed so tightly to the considerations that one must make. Whether one must consider some entity is a different question than what the relevant considerations are, and how relevant they should be. Whether I must consider my mother's health, for instance, has little to do with what considerations about my mother's health I must consider. In fact, I need not know much about my mother's health to know that I must consider my mother's health. My mother could even be quite healthy, but it would still be incumbent upon me to consider her health. It is my claim that we humans bear the responsibility of considering morally; and that this consideration is independent of our determination of the significance of an entity.
} 
And then one might ask the third question, which is more a question about moral significance than a question about consideration. That is, one might ask how much weight we have to place on those peculiarities of the animal that we have deemed relevant enough to consider. Since, in the case of dogs, we might agree that we must look out for a dog's interests conceived broadly to be feelings, emotions, nutritional needs, and so on - we might then suggest that since we are the stewards of these animals, we should give great attention to their nutritional needs, and perhaps some attention to their emotional needs, while we do not need to give the same attention to wild coyotes.

One might be inclined to object that this reformulation begs the question, since the determination of whether an entity is considerable only appears possible in virtue of the attributes specific to that entity. But this is not the way that I mean it. Rather, the moral considerability hypothesis that I present depends on the claim that we rational beings, we humans, we moral agents, are, in the end, constitutively, moral considerers. If we grant the claim that, at base, our obligation as moral agents is to consider reasons, then the burden falls on our shoulders to find the reasons implicit or explicit in all of our interactions with others and with entities in the environment. Thinking of moral considerability in this way, far from begging the question, resets the burden of proof implied by the moral status question entirely. Instead of depending on other entities to demonstrate to us what is so special about them, we must rely on our own resources to determine what is relevant and significant about other entities. In a sense, the traditional conception of the question of moral considerability - which is to say, the question of moral status - is very similar to the question about species that we discussed above. The term "species" is considered to be a rigid and immutable category, and the notion of "moral status" is also thought to be a rigid and immutable category. This dilemma between environmentalists and animal liberationists is falsely concrete because of our own historical predilection to make sense of moral status by means of appealing to attributes intrinsic to the beings themselves, like belonging to a certain group.

The point that I am trying to make in this paper is that, though the terrain of our earth may be changing at any time, we always bear the burden of considering both the species and the system in all cases. Though ecosystemic changes may be, at times, due to alterations made by humans and at other times sometimes just naturally changing, our moral thinking on the matter should remain consistent. It can, if we conceive of the question of moral considerability as more a question about what we must do, as rational agents, than as a question about which characteristics qualify certain beings for moral status. That has never been, and never should be, the question. 


\section{OBLIGATIONS TO CHILDREN, PETS, AND SPECIES}

I mentioned at the beginning of this paper that the question of the moral considerability of a species is complicated by the blurring of the line between human and non-human, by the introduction of beastly XGMAs into the landscape. As these animals invade the landscape - and it is a virtual certainty that they will - they will begin to transform the landscape. So now we must ask the central question:

If we are liberationist in our sentiments regarding animals and the environment, but environmentalist in our predilection to believe that sometimes the concerns of the system override the welfare of individuals within that system, do we not have special obligations to those animals that we have made in our image, with our very own genes?

It is little stretch of moral reasoning to argue that we have an obligation to tend to the interests of beings that we create: we create our children, for instance, and take ourselves to be deeply responsible for their well being. Partly, these are obligations of love that derive not from the particular attributes that the beings have - it is not because they are sentient or because they are alive - but rather specifically because our children bring us the type of joy that other beings do not. Partly, these are obligations of societal and biological egoistic expectation, derived from social and genetic imperatives to provide for ourselves or perish. Partly, as well, these are obligations that emerge because children are themselves persons, or at least potential persons, with the potential for welfare and interests and reason and all of the rest of the attributes that have historically been isolated as relevant enough to confer status upon that being. More importantly, I think, these are obligations of self-commitment, obligations to which we are bound because we have taken them on ourselves, because we have created these beings. When we create a child, we effectively bind ourselves to be their caregiver. In part, we bind ourselves by relinquishing control of our genetic material, for which we are responsible. ${ }^{25}$ This is even true in cases where we might not necessarily have willed the child into existence, as is the case with accidental pregnancies or pregnancy with multiples. Until our child is old enough to care for itself, or unless a foster parent or the state can take over responsibility for the child, we biological parents maintain the moral responsibility of caring for the child.

Simply having the attribute of being our own creation, of course, is not enough to establish our responsibility to the entity in question. We also create coffee mugs, chocolate bars, and aluminum foil, none of which, many

\footnotetext{
${ }^{25}$ Importantly, it is not the genes themselves that establish this responsibility, but rather our responsibility for our actions and for our own genetic material.
} 
would want to say, we have any obligation to steward. However, taking XGMAs as a whole - which we must do as we are coming to a determination about the relevance and significance of a particular entity - it becomes plain that XGMAs have more in common with creatures of our creation, like children, than they have in common with objects of our creation, like coffee mugs and chocolate bars. For starters, they result from actions that we have taken to relinquish our genetic material. One might be inclined to think that this difference has something to do with the harm that can come to creatures of our creation, but I would beg to differ. While the capacity to experience harm is certainly important as to the determination of what to do about a certain entity (e.g., which are the relevant and significant considerations), what is really important regarding our obligation to consider any entity is that we be capable of recognizing the important distinction between a coffee mug and a creature of our own creation. ${ }^{26}$

One might then be inclined to think that this difference has something to do only with the agency of the creators, and nothing to do with those who do not actively engage in the creation; that somehow obligations adhere only to those persons who singly and actively engage in the creation of the XGMA. In part, at least, this is what appears to give rise to our obligations as parents. Our children are our own creations, with direct genetic lineage from parent to child. But obligations to others are not necessarily the result of actions for which we're directly responsible. We have obligations to many entities, human and non-human, that no single one of us has actively and willfully created, but that are instead caught up in a system that created them: abandoned children, abandoned pets, insane people, parents, future generations, to name just a few.

\footnotetext{
${ }^{26}$ That creatures of our own creation are creatures matters, of course. We do not have the same obligations to robots as we do to living, experiencing organisms. Robots, as far as we know, do not have experiences. For similar reasons, we also do not have the same obligations to single-celled organisms that we have to full-blown mammals. Single-celled organisms probably also do not navigate the world in the same way that beetles, mice, parakeets, and orangutans do. There are many other salient considerations related to creatures of our own creation. In this case, XGMAs carry our genetic material - they are ours in a strong biological sense - and they are not accidents of the universe. This, I would think, ties us more closely to them than even our pets. However, a referee notes that such an observation might fall prey to the concern that I have taken pains to do away with above - namely, a sort of genetic essentialism. This would be missing the point. Much of the point of the above thesis is that it is fruitless to attempt to ascertain the root of our obligations to other entities via generalizations about their attributes do they think?, can they be harmed?, do they desire?, are they a member of our species? and so on. Rather, the thesis asserts that in order to understand our obligations at all, we must interrogate the many relations that we have with entities in the world; we must consider as fully as we are epistemically able the many considerations that make up these relationships. In this sense, the thesis is deeply pluralistic. Insofar as XGMAs are both (a) made up of some of our own genetic material and (b) no freakish accident of nature, one could argue, as I am, that one's normative commitments to attend to the creatures are strengthened.
} 
It would be a further mistake to think that this moral relationship is rooted exclusively in genetic similarity. To some extent, we also have obligations to our pets in this way too. When we take them under our wing, we accept them as our own responsibility, our charge. This is certainly true if we purchase or breed a pet and make it a member of our family. In this case, we bind ourselves to be its steward. But it is also even true even if the pet's existence in our lives occurs circumstantially. If we see a lost and injured dog in the street, we often will say, "something must be done about that dog," and we either do something about the dog ourselves, find somebody to do something about the dog, or feel guilty for not having provided aid. ${ }^{27}$ We do this even though we do not think that lost dogs have the same needs as rational or capable humans. In effect, we bind ourselves to pets in light of their needs, but not because of their needs, and in doing so commit ourselves to care for them, even if we are not culpable for having brought them into their present circumstance. We do so because we are good and responsible people, not because our pets need us. Importantly, we also do not do this because we expect them to reciprocate the favor. We simply take the welfare of these creatures on as our own responsibility because we understand our own ability to provide for them, and their own inability to provide for themselves. Moreover, we are also not released from these obligations just because we create these beings, or take them on, for a specific egoistic purpose. If we purchase a pet to please our children, we often say that we cannot use it solely for the pleasure of our children, as if, say, our children like to play toss with the cat or squish it under their bikes. ${ }^{28}$ The moral standing of the pet obtains regardless of its supposed use to us.

The important point, instead, is that our obligations to XGMAs stem from our active involvement in their creation, from our release of control over our own genetic material, and from their genetic relation to us through this release. This obligation is easy to recognize if we parse the question of moral status deontologically, in terms of moral considerations that we must make, as opposed to capacities that they must prove to us. Neither pets nor infants exhibit the attributes that would, under most other circumstances, qualify them for full moral status. However, we give great credence to the

\footnotetext{
${ }^{27}$ I can't speak for everyone on this count, but I take it that this is a fairly common sentiment.

${ }^{28}$ The same should hold for domesticated farm animals as well, but this is a topic for a different paper. Simply, the objection that I am anticipating runs thus: that we create and breed cows exclusively for our use; they would not exist were it not for this use; and since all of their value is relational and dependent upon this use, we should therefore be able to use them in whatever way we so desire. This argument does not follow, as has been argued in numerous places. We are not released from treating people with respect even if we breed them to be our slaves. Similarly, we are not released from treating animals with respect even if we breed them to be our chattel.
} 
needs of our children, and often also to our pets, because their predicament forces considerations upon us. Our children are our biological progeny, they are helpless, and we have taken responsibility for them early in their lives. Our pet dogs are domesticated creatures in need of aid, for whom we've often already taken responsibility. In birthing, adopting, and raising these entities, we take them under our wing, effectively obligating ourselves to care and provide for them. We recognize that we must, at the very least, consider them and their interests, since we take responsibility for our own actions in bringing them into being. This is an obligation to which we hold ourselves, by virtue of who we are, not who they are. Where we cannot provide this care ourselves, the collective maintains obligations to help us fulfill our responsibilities.

As I see it, much of the same logic that applies to creatures of our collective creation applies to XGMAs. We needn't be concerned about the blurring of distinctions between humans and non-humans at all. We must instead ask ourselves a simple question: What must we consider? And this question should be followed by the question of moral relevance, which can then be followed by the question of moral significance. In the case of XGMAs, we can answer the question of moral considerability rather handily: the fact that we have taken steps to create, from whole cloth, new animals, new creatures, new hybrids, obligates us to take the interests of those beings to heart. In creating them, we have taken on their existence, taken their ends as our own, made their ends part of our ends, and obligated ourselves to treat them appropriately. This is a morally relevant consideration. (It is not, however, the only morally relevant consideration. It is just one consideration among many.)

Of course, our own children do differ markedly from XGMAs, so this comparison only goes so far. For one thing, our relationship to XGMAS is quite different than our relationship to our children. We are mostly only distantly responsible for having brought XGMAs into existence, where this is probably not true with our own children. Our children are ours, and there is a clear and direct parent with responsibilities to each and every child. Where there is not a clear parent, we collectively take the responsibility upon ourselves to ensure that children do not grow up without care. In this case, we must fall back on the collective "we" to argue for responsibilities to human children. Just as the collective "we" has responsibilities to our children, so too does this collective "we" have a responsibility, a moral obligation, to step in and help out in the case of XGMAs. In this case, there is no clear parentage. But there is, however, a sense in which society must take responsibility for the interests of XGMAs themselves and the consequences of creating XGMAs. In this case, the XGMAs are our responsibility because we have lost control of our genetic material. 
We don't have to love XGMAs like our children, of course, but we must recognize that in creating them, in relinquishing control of our genetic material, we obligate ourselves to them in a way that we do not obligate ourselves to "natural" animals. XGMAs wouldn't exist at all were it not for us. Their limbs are our limbs; their hearts are our hearts. What is important to recognize, however, is that we must consider these beings, and this aspect of their existence specifically, regardless of their particular attributes. The attributes are important, of course, and in determining how we are going to consider them, we should investigate the salient attributes for sure. But, as I mention in the above section, this is a question that is best answered when asking ourselves questions of moral relevance. What attributes are relevant in this case? All of the classic ones - sentience, welfare, rationality, being the subject of a life - to be sure; but also some other ones: being an offspring and a rationally chosen product of humans. That too is relevant. Clearly, for example, if the XGMA is a canine-human hybrid that differs only from a pitbull in that it has human DNA, a morally relevant concern is probably not going to be whether we must train it in linear algebra. This is not a morally relevant question. However, concerns about its well-being and welfare will be relevant, and we must ask ourselves whether and how these concerns can best be attended to; as well, we must answer the difficult question of our own self-committed obligation to our own creations can be understood in light of this welfare.

Now, to the final question: Is the threatened modification of the environment enough to warrant intervention on moral grounds, even if it means undercutting the interests or welfare of our offspring?

If we parse the question of moral status along the lines that I have outlined above, we can answer the question about our own obligations without offending one or the other side. We can recognize that we have a strong obligation to consider the interests of the environment - recognize, in other words, that the environment and its inhabitant species are morally considerable - and we can also recognize that the species that we create are morally considerable in themselves.

Environmentalists argue that we should intervene to eradicate an invader species because a species and ecosystem has moral priority, but liberationists argue that we should not intervene in the lives of the invader species, because all animals are equal. On its face, it appears that the environmentalist would grant no status to the individual. But the environmentalist does not need to go this far, and in fact, often does not. All she must do is grant that the individual is morally considerable, perhaps also arguing for certain relevant reasons (the second question), and then proceed from the standpoint that the environment is also considerable. Likewise, on its face, it appears that the animal liberationist would grant no status to the system. 
But neither does the animal liberationist need to go this far. All he must do is grant that the environment is considerable, for certain relevant reasons, and then continue with his arguments. When it comes time to determine what to do, the question of significance must be battled out, but this can be done by devising a calculus that clearly lays out and ranks the relevant reasons. ${ }^{29}$

In more practical scenarios, it appears that both sentiments - environmentalist and liberationist - can work happily together. Programs like Operation Catnip in Gainesville, Florida - "An all-volunteer organization dedicated to humanely reducing stray and feral cat populations through sterilization" - do not simply eradicate feral cats as though they have no welfare, but instead seek to diminish their impact on the environment while also minimizing harm to the cats. ${ }^{30}$ Why is this? Partly, I would think, because the two doctrines are not nearly as incompatible as they have been made out to be by rigorous theoreticians like Sagoff, Callicott, and others. Instead, both positions rely upon the supposition that factors like welfare, systemic relations, and lineage are considerations relevant to moral decision making. In the end, what is in dispute is the significance of each moral consideration - and on this count, environmentalists and liberationists may have cause to bicker - but what is expressly not in dispute is whether the environment or the inhabitants of the environment are considerable at all.

When we face the question of what to do with XGMAs as they emerge into our food supply, as they transform our environment, we should not be deterred from the ethical question of status because of our commitments to one or the other standpoint, environmentalism or liberationism. Both standpoints can work harmoniously together. We must instead tweak the question that we ask ourselves to better make sense of the changing face of the environment. Doing so will open the door for us to speak intelligibly of

\footnotetext{
${ }^{29}$ At this stage, one might be inclined to object that the call to devise a calculus only shifts the debate between environmentalists and animal liberationists to a different level. But this is not true. When taken as explained above, environmentalists and liberationists are arguing about first principles: about which attributes, which characteristics, qualify an entity or an ecosystem for moral status. The claim is the following: that we must consider an entity (as worthy of status) because of $\mathrm{X}$ attribute. This is quite a bit different than the claim that follows in the wake of application of the moral considerability thesis. On my account, environmentalists and liberationists can meet in the middle because the moral considerability claim is much thinner: that we must consider all reasons. Whether the reasons are relevant and have significance is another matter entirely, and on this, environmentalists and liberationists may have reason to battle some matters out. My claim is not to have resolved the debate between environmentalists and liberationists, but only to have opened the door to pragmatic resolution of some of the foundational dispute. My sense of the current debate is that animal liberationists, when pressed, would also find sympathies for the positions advocated by environmentalists; and vice versa.

${ }^{30}$ Thanks to Richard Haynes for suggesting this example. Read about Operation Catnip at: http://www.operationcatnip.org/
} 
our concerns for the welfare of XGMAs while also incorporating our concerns for the overarching environment.

\section{CONCLUDING REMARKS}

In this paper, I have argued that we have special obligations to XGMAs. I have done so by proposing that these obligations do not stem from their DNA or their relation to us, but instead stem from our own commitment to XGMAs upon their creation. If they are to escape into the environment, then we cannot treat them as morally irrelevant in the way that environmentalists might argue about a "natural" invader species; we cannot negate and ignore these interests and obliterate them as one might obliterate the sus scrofa of Hawaii. ${ }^{31}$ We have special obligations to consider the interests of the XGMA animals themselves, precisely because they are, in a sense, our own offspring, our own charge. At the same time, because we must consider the interests of the overall ecosystem - ecosystems are morally considerable too - we cannot neglect the environmentalist argument that invader species, and particularly XGMA invader species, must be kept, at all costs, from doing harm to the environment. What we ought not to do, however, is to argue that either one or the other - the habitat or the individuals - are not at all considerable.

I have also argued that environmentalists and liberationists, as traditionally conceived, face a conceptual problem that is uncovered by recent developments in genetic engineering. Namely, the species "human" rests on a fallacious presumption about the rigidness of categories in biology. Yet both positions hold fast to a conception of the individual agent that has him take responsibility for his own actions, which is upheld by deference to the question of moral considerability. Recasting the question of moral status as a deontological question, as a question about what we must do, instead of what attributes another being must have, allows us to circumvent the natural tensions between the two positions.

Throughout, I have been assuming that the question of whether we should even create an animal is more or less moot. GM Animals are here already, and there is little we can do at the moment to attend to this fact. It has been my purpose to argue that if we create these animals - which we already have - then we have special obligations to them that can only really be understood if we reinterpret the framing of the question of moral

\footnotetext{
${ }^{31}$ For the record, I do not think that one should "obliterate" the sus scrofa of Hawaii by shooting them or by causing significant harm to them. Rather, I think that interested parties should seek to find ways of remedying the problem that take into consideration the concerns of both environmentalists and liberationists, perhaps in the spirit of Operation Catnip mentioned earlier.
} 
considerability. Yet, if we do not want to face the acute moral dilemma in which we have to break our special moral obligations to our offspring, then we ought not to go introducing them into the world. The development of XGMAs generates the paradoxical standpoint that environmentalists and liberationists will be obligated, according to their own principles, to eradicate a species for which they have initially taken responsibility.

The reality of a cataclysmic XGMA invasion is perhaps a long way off, an outgrowth of some grand post-apocalyptic vision in which laboratories and production facilities become so dilapidated and underfunded that the modified human offspring burst from their cages and overtake the land. Unless scientists and planners are extraordinarily reckless with their bioconfinement methods, we should probably not be worried about cataclysmic consequences. Our surrounding environment will not really be occupied by monsters and chimeras, and our humanness will not be challenged in any noticeably significant way. However, entertaining the prospect of such an invasion unveils contradictions in our assumptions about what we must consider; forcing us to rethink our relationship to ourselves, our fellow creatures, and our environment. This, I should think, is reason enough to entertain the prospect that Dr. Moreau's monsters may one day escape from his island.

\section{REFERENCES}

Barrett, R. H. and G. H. Birmingham, "Wild Pigs," in S. E. Hygnstrom, R. M. Timm, and G. E. Larson (eds.), Prevention and Control of Wildlife Damage - 1994, Cooperative Extension Division, Great Plains Agricultural Council, United States Department of Agriculture, Animal and Plant Health Inspection Service, D65-D70.

Bok, H., "What's Wrong with Confusion," The American Journal of Bioethics 3(3) (2003), 25-26.

Callicott, J. B., "Animal Liberation: A Triangular Affair," Environmental Ethics 2 (1980), 311-338.

Callicott, J. B., Companion to the Sand County Almanac (University of Wisconsin Press, Madison, 1988).

Callicott, J. B. and M. Nelson (eds.), The Great New Wilderness Debate (University of Georgia Press, Athens, 1998).

Carruthers, R. I., "Biological Control of Invasive Species, a Personal Perspective," Conservation Biology 18 (Feb 2004), 54-58.

Conner, S., "Scientists Could Make GM Beef with Healthy Fish Oils," The Independent, February 5, 2004.

W. Cronon (ed.), Uncommon Ground: Rethinking the Human Place in Nature (W. W. Norton, New York, 1996).

Dennett, D., Darwin's Dangerous Idea (Touchstone, New York, 1995) 35-39.

Dennis, C., "China: Stem Cells Rise in the East," Nature 419 (2002), 334-336. 
Didur, J., "Re-embodying Technoscientific Fantasies: Posthumanism, Genetically Modified Foods, and the Colonization of Life," Cultural Critique 53 (2003), 101102.

Dowie, M., "Talking Apes, Flying Pigs, Superhumans with Armadillo Attributes, and Other Strange Considerations of Dr. Stuart Newman's Fight to Patent a Human/Animal Chimera." (Gods And Monster) Mother Jones (Jan-Feb 2004), v29 i1 p. 48(8).

Goldstein, R. S., M. Drukker, B. E. Reubinoff, and N. Benvenisty, "Integration and Differentiation of Human Embryonic Stem Cells Transplanted to the Chick Embryo," Developmental Dynamics 225 (2002), 80-86.

Gould, S. J., The Mismeasure of Man (W. W. Norton and Company, Inc., New York, 1981).

Hale, B., The Roots of Moral Considerability, Ph.D. Dissertation, Stony Brook University (2004), UMI Number: 3161048.

Highfield, R., "How I Chopped the Fat from Bacon... Wilbur the $300 \mathrm{~kg}$ Boar Will Help Farmers to Breed Leaner, Tastier, More Profitable Animals," The Daily Telegraph, London (Nov 26, 2003), pp. 20.

Katz, E., "Is There a Place for Animals in the Moral Consideration of Nature?" Ethics and Animals 4 (September, 1983).

Krieger, L. M., "Scientists Put a Bit of Man into a Mouse," Mercury News, (8 December 2002), Available from: http://www.bayarea.com/mld/mercurynews/ 4698610.htm.

Leopold, A., The Sand County Almanac (Oxford University Press, New York, 1966).

Lodge, D. M. and K. Shrader-Frechette, "Nonindigenous Species: Ecological Explanation, Environmental Ethics, and Public Policy," Conservation Biology 17 (Feb 2003), 31-38.

Midgley, M., "Biotechnology and Monstrosity: Why We Should Pay Atention to the 'Yuk Factor'," The Hastings Center Report 30(5) (Sept. 2000), 7-15.

Norton, B., Toward Unity Among Environmentalists (Oxford University Press, New York, 1991) 222.

Ourednik, J., J. D. Flax, W. M. Zawada, C. Hutt, C. Yang, K. I. Park, S. U. Kim, R. L. Sidman, C. R. Freed, and E. Y. Snyder, "Segregation of Human Neural Stem Cells in the Developing Primate Forebrain," Science 293 (2001), 1820-1824.

Pollack, A., "So the Fish Glow, but Will They Sell?" New York Times (Jan 25, 2004a), p. BU5 Col. 01.

Pollack, A., "No Foolproof Way Is Seen To Contain Altered Genes," The New York Times (Jan 21, 2004b), p. A10 col 05.

Richardson, D. M., P. Pysek, M. Rejmanek, M. G. Barbour, F. D. Panetta, and C. J. West, "Naturalization and Invasion of Alien Plants: Concepts and Definitions," Diversity and Distributions 6 (2000), 93-107.

Robert, J. S. and F. Baylis, "Crossing Species Boundaries," The American Journal of Bioethics 3(3) (2003), 1-13.

Rollin, B. E., The Frankenstein Syndrome: Ethical and Social Issues in the Genetic Engineering of Animals (Cambridge University Press, New York, 1995).

Sagoff, M., "Animal Liberation and Environmental Ethics: Bad Marriage, Quick Divorce," Osgood Hall Law Journal 22 (1984), 297-307.

Savulescu, J., "Human-Animal Transgenesis and Chimeras Might Be an Expression of Our Humanity," The American Journal of Bioethics 3(3) (2003), 22-25. 
Siegel, A., "The Moral Insignificance of Crossing Species Boundaries," The American Journal of Bioethics 3.3 (2003), 33-34.

Stowers, A. W., L-H. Chen, Y. Zhang, M. C. Kennedy, L. Zou, L. Lambert, T. J. Rice, D. C. Kaslow, A. Saul, C. A. Long, H. Meade, and L. H. Miller, "A Recombinant Vaccine Expressed in Milk of Transgenic Mice Protects Aotus Monkeys from Lethal Challenge with Plasmodium falciparum," Proceedings of the National Academy of Sciences, Early Edition online (December 17, 2001).

Tennant R. W., S. Stasiewicz, J. Mennear, J. E. French, and J. W. Spalding, "In The Use of Short- and Medium-term Tests for Carcinogens and Data on Genetic Effects in Carcinogenic Hazard Evalaution," (IARC Scientific Publications No. 146, International Agency for Research on Cancer, Lyon, 1999). 123-150.

Union of Concerned Scientists, "Genetically Engineered Salmon" (February 1, 2001), http://www.ucsusa.org/food_and_environment/biotechnology/page.cfm? pageID $=327$

Varner, G. E., "Can Animal Rights Activists Be Environmentalists?" in D. E. Marietta, Jr. and L. Embree (eds.), Environmental Philosophy and Environmental Activism (Rowman and Littlefield Publishers, Lanham, MD, 1995).

Varner, G., In Nature's Interests? Interests, Animal Rights, and Environmental Ethics (Oxford University Press, New York, 1998).

Warren, M. A., Moral Status: Obligations to Persons and Other Living Things (Oxford University Press, New York, 1997).

Wells, H. G., The Island of Dr Moreau (Tor Books, New York, 1996).

Philosophy Department

University of Colorado, Boulder

Boulder, CO, 80309-0232

USA

E-mail:bhale@colorado.edu 